\section{Exílio e}

\section{afastamento:}

considerações sobre uma hermenêutica da distância?

\author{
Silvina Jensen $\left[{ }^{*}\right]$ \\ Mauricio Parada [**]
}

[*] Universidad Nacional del Sur (UNS) - Bahia Blanca - Buenos Aires, Argentina. Consejo Nacional de Investigaciones Científicas y Técnicas-CONICET Buenos Aires, Argentina. E-mail: sjensen@criba.edu.ar

ORCID: http://orcid.org/0000-0002-9166-8852

[**] Pontifícia Universidade Católica do Rio de Janeiro (PUC-Rio) - Rio de Janeiro (RJ), Brasil.

E-mail: mauriciobparada@gmail.com

ORCID: http://orcid.org/0000-0003-2959-5215
Resumo: Este texto apresenta os trabalhos publicados no dossiê "Exílio e afastamento: considerações sobre uma hermenêutica da distância”, e, para tal, propõe uma reflexão sobre a categoria de exílio. A história do século XX, atravessada por crises, produziu massivamente populações de deslocados, sujeitos instáveis em um tempo de mudanças contínuas. Em torno da situação de estranhamento orbitam novas formas narrativas, possibilidades de saberes, tendo sido criados distintas práticas disciplinares. Nesse sentido, consideramos que o estudo das diversas experiências exilares contribui para a ampliação de nosso entendimento sobre os dilemas de nossa contemporaneidade.

Palavras-chave:Exílio; Contemporâneo; Deslocamento.

Exile and exclusion: considerations about a distance hermeneutics?

Abstract: This dossier gather articles that analyze different historical experiences marked by the condition of exile. Twentieth-century history has massively produced displaced people, unstable subjects in a time of continuous change. Around the situation of estrangement orbit new narrative forms, possibilities of knowledge and different disciplinary practices were created. In this sense, we consider that the study of the various experiences of exile contributes to broadening our understanding of the dilemmas of our contemporaneity.

Keywords: Exile; Contemporary; Displacement. 
A semântica dos deslocamentos é complexa: apátridas, deslocados, fugitivos, clandestinos, desenraizados, imigrantes, emigrados e muitos outros termos compõem um campo vasto. Uma avaliação terminológica rigorosa seria necessária para ordenar uma mescla de registros que descrevem situações jurídico-sociológicas, referências a condições existenciais e termos que remetem a contextos históricos. De todo modo, esse conjunto indica condições de profunda instabilidade e insegurança (Nouss, 2015).

Nessa galeria lexical, o termo exílio destaca-se. Consideramos que a amplitude de significados associados a essa categoria sustenta uma importância conceitual e metodológica específica: a experiência exílica representa um núcleo existencial/jurídico/social comum a todos os fenômenos de mobilidade forçada em nossa contemporaneidade, de tal modo que ela pode permitir a compreensão de outras terminologias sem recobrir suas especificidades.

Utilizar o termo exílio para tratar de milhões de trajetórias de deslocamento que balizaram a experiência coletiva e global do último século indica, por conseguinte, uma reconfiguração do sentido de exílio. A trajetória exilar trama uma relação tensa entre histórias e memórias, constitui biografias tocadas pela ruptura e pela descontinuidade e produz relatos que aspiram a uma coerência imaginária - esforços narrativos que lançam desafios às categorias de tempo, espaço e identidade.

Vivendo na crise dos Estados nacionais europeus depois de 1918, os exilados da contemporaneidade deslocaram-se por uma geografia instável, na qual o passado de suas existências desaparece para dar lugar a um futuro radicalmente novo, em que eles não têm pertencimento garantido, e sua tarefa de sobrevivência é um desafio físico e de produção de sentido. O presente dossiê conta com estudos sobre as diversas dimensões da experiência exilar contemporânea, trabalhos que analisam testemunhos, ações institucionais e campos de conhecimento surgidos como desdobramento dos eventos violentos associados ao fato exilar. No entanto, pensar o exílio é uma proposição que vai além do estudo de caso. Os trabalhos publicados nesta edição da revista Tempo partem da experiência do exílio para discutir as relações complexas da história com a literatura, com o campo psicanalítico e com práticas políticas diversas.

\section{Possibilidades de análise}

O exílio tem sua origem na velha prática do banimento, mas os exilados sem pátria são uma criação do Estado do século XX. Muitos pertencem à extensa galeria de personagens do deslocamento: os expatriados moram em outro país, geralmente por motivos pessoais ou sociais, sem sofrer as mais rígidas interdições; os emigrados gozam de uma situação ambígua, em que a possibilidade de escolha não lhes foi de toda retirada; funcionários coloniais, missionários, assessores técnicos, mercenários e conselheiros militares podem, em certo 
sentido, viver longe de sua pátria, mas não foram banidos. No entanto, o surgimento massivo de exilados sem pátria foi uma dimensão severa de sucessivas crises políticas, ideológicas e militares ocorridas nas primeiras décadas do século XX. Milhões de homens e mulheres movendo-se em uma extensão territorial global; esse é o cenário que configura a dimensão do contemporâneo.

Nesse sentido, ao considerar as transformações que marcam nosso presente, François Hartog (2013) observa que o homem deslocado foi uma figura importante na lenta construção de uma nova forma de historicidade. Atualizando o conceito de "brecha", o autor afirma que a temporalidade vivida pelos deslocados de nosso tempo ocorre no interior de um gap temporal, em que o tempo histórico está suspenso, um tempo desorientado, situado entre dois abismos: um passado que não está abolido, mas que nenhuma orientação pode oferecer, e um futuro do qual não se faz ideia de como será. Vivendo em um tempo em trânsito, esse deslocado, exilado entre distintas temporalidades, será um observador agudo desse novo tempo.

Nesse sentido, os exilados foram os primeiros a transformar a experiência dos horrores do século XX em objeto de pensamento. Por isso, sua contribuição ao pensamento crítico foi, e ainda é, tão fundamental para a escrita da história. O desenraizamento nacional, a perda do trabalho, das ligações familiares, da língua e do contexto social e cultural transformam o exilado em um personagem dotado de uma condição fundamental para a construção de uma análise crítica do mundo contemporâneo: a condição do estranhamento e da distância.

Acompanhamos Traverso (2012) em sua proposição, ou seja, no que ele denomina hermenêutica da distância. Vivenciando o estranhamento proporcionado pelo afastamento que lhe foi imposto, os exilados e apátridas são obrigados a observar, sem nenhuma empatia, o mundo do qual foram expulsos e enfrentar eticamente o mundo para o qual se dirigiram. Crítica e compromisso (ético) são as bases da hermenêutica, quase existencial, que se tornam incontornáveis para o estrangeiro radical. A potência presente no exilado desse novo tempo é ao mesmo tempo sua tragédia, ou seja, sua impossibilidade de retorno, uma vez que o mundo material, jurídico, cultural ou pessoal foi aniquilado, transformando a distância em impossibilidade. Nesse caso, o lugar de exilio torna-se também espaço imaginativo. Diante do novo mundo de acolhida e com um futuro às vezes imprevisível pela frente, muitos reinventam suas identidades e trajetórias de vida. Um novo começo, com outro nome, religião e profissão, marca as histórias desses desenraizados.

Cabe, portanto, uma breve reflexão sobre as relações entre a experiência exilar e a escrita literária. Said (2002), a ler Lukács, sustentou que o romance, forma literária criada a partir da fantasia, emana de uma realidade marcada pela instabilidade, na qual sujeitos comuns, mesmo os itinerantes e deserdados, pensam poder construir um mundo novo. No 
romance, diferentemente de na epopeia, o destino é desdito, e apresentam-se às personagens e aos leitores outros mundos possíveis. Podemos nos perguntar de que modo a literatura do exílio assumiu seu lugar como um topos da experiência humana. Ou ainda como se realiza a experiência dos intelectuais e escritores exilados, na medida em que o exílio impacta diretamente seu ofício, a saber, a produção da inteligibilidade sobre si e seu entorno. Essas questões mobilizam Federico Gerhardt na escrita de seu artigo "Decir (en) el exilio, en el siglo XX: cuestiones terminológicas, literarias y editoriales. Aproximaciones con vistas al exilio de la Guerra Civil española", sobre os dilemas e impasses dos escritores espanhóis exilados a partir da derrota republicana e pelo início do governo franquista.

No campo dos estudos sobre trajetórias de intelectuais, publicamos os textos de Benedetta Calandra, "Cultural philanthropy and political exile: the Ford Foundation between Argentina and The United States (1959-1979)", e de Luiza Nascimento dos Reis, "O exílio africano de Paulo Farias (África ocidental, 1964-1969)”. A partir de casos coletivos ou individuais, ambas trazem importantes contribuições para a compreensão da participação de pesquisadores latino-americanos na formação dos campos disciplinares nas áreas de ciências sociais.

Calandra faz uma análise das políticas de financiamento e apoio a intelectuais argentinos fomentada pela Fundação Ford, nos Estados Unidos. O artigo estuda a atuação da agência americana a partir de 1959, momento crítico das relações interamericanas durante a Guerra Fria. A pesquisa está baseada em fontes com informações sobre as ações que permitiram a diversos intelectuais escaparem das perseguições políticas iniciadas no final da década de 1950 na Argentina.

O trabalho de Luiza Nascimento, por sua vez, apresenta a trajetória de um intelectual negro brasileiro após o Golpe de 1964. Em seu artigo, a autora descreve, a partir da correspondência de Farias com Pierre Verger, não apenas um percurso exilar, mas principalmente elementos para compreendermos a construção do campo de estudos africanos no Brasil.

O sujeito exilado sai sem saber se retorna à sua pátria. Seu projeto político e de vida foi derrotado, e, a partir desse dado, ele poderá ou não se reinventar no exterior, ou simplesmente desistir. Suas perspectivas, entre elas a do fim do exílio, orientarão a forma com que ele se relacionará com seu passado, deixado na terra natal, e recriará seu presente e futuro. Fato é que o exílio impõe a ruptura com um mundo de referências basilares, obrigando o exilado à inescapável experiência do desenraizamento (Todorov, 1999). A diferença está no que fazer a partir dessa experiência, que, em um primeiro momento, expressa apenas perdas dolorosas.

O luto doloroso decorrente da sobrevivência e a dificuldade do retorno são um campo de estudos que radicaliza o compromisso ético dos historiadores e cientistas sociais com seu presente. A mobilização de testemunhos como fonte para a pesquisa e a atenção para as trajetórias individuais e coletivas em um contexto de reconstrução são problemas analisados 
por Mario Ayala em seu artigo "Reaparecer en el exilio": experiencias de militantes argentinos sobrevivientes de desaparición forzada en Venezuela (1979-1984)”. O autor aborda com competência os problemas surgidos no processo de chegada a outro país e as relações, por vezes tensas, entre os diversos agentes presentes no processo exilar.

Em uma abordagem próxima, na qual sobressai o tema do pós-exílio, María Soledad Lastra analisa o processo de elaboração conceitual do termo "retorno", relacionando-o com o campo dos direitos humanos e da saúde mental. Em seu texto “Dejar de ser síntoma con el silencio”: la inscripción del exilio-retorno en el campo de la salud mental en la posdictadura argentina (1983-1986)", a autora criteriosamente analisa a produção teórica e clínica das equipes de saúde mental de instituições argentinas dedicadas à recepção de exilados argentinos nos anos 1980, trazendo uma abordagem original sobre o problema do retorno.

Ao editarmos este dossiê, acreditamos apresentar ao leitor a possibilidade de avaliar o tema tão incômodo quanto presente de forma complexa e múltipla. A experiência do deslocamento, que hoje atinge milhões de seres humanos, não é apenas um tema que desafia os conceitos legais ou a norma jurídica. Mais do que isso, como categoria trágica, o exílio/deslocamento é parte do lento e desafiador processo de nossa contemporaneidade de redefinição de nossas concepções de tempo, espaço e cultura. 


\section{Referências bibliográficas}

AGAMBEN, G. O queé ser contemporâneo? E outros ensaios. Chapecó: Argos, 2009.

ARENDT, H. Entre o passado e o futuro. São Paulo: Perspectiva, 1979.

HARTOG, F. Regimes de historicidade. Belo Horizonte: Autêntica, 2013.

NOUSS, A. La condition de l'éxile. Paris: Editions de La Maison des Sciences de l'Homme, 2015.
QUADRAT, S. (Org.). Caminhos cruzados: história e memória dos exílios latino-americanos no século XX. Rio de Janeiro: FGV, 2011.

SAID, E. Reflexões do exílio e outros ensaios. São Paulo: Companhia das Letras, 2002.

TODOROV, T. O homem desenraizado. Rio de Janeiro: Record, 1999.

TRAVERSO, E. L'histoire comme champ de bataille: interpréter les violences du $\mathrm{XX}^{\mathrm{e}}$ siècle. Paris: La Découverte, 2012. n. 359

\section{Errata}

DOI: 10.1590/tem-1980-542x2019v250314

Para o texto de apresentação do dossiê: Exílio e afastamento: considerações sobre uma hermenêutica da distância? Publicado no fascículo 25-2, citado como:

JENSEN, Silvina; PARADA, Mauricio. Exílio e afastamento: considerações sobre uma hermenêutica da distância?.Tempo, Niterói, v. 25, n. 2, p. 405-410, Aug. 2019. Available from <http://www.scielo.br/scielo.php?script=sci_arttext\&pid=S141377042019000200405\&lng=en\&nrm=iso $>$. access on 10 Oct. 2019. Epub July 15, 2019. http://dx.doi.org/10.1590/tem-1980-542x2018v250206.

\section{ONDE SE LÊ:}

“O trabalho de Luiza Nascimento, por sua vez, apresenta a trajetória de um intelectual negro brasileiro após o Golpe de 1964. Em seu artigo, a autora descreve, a partir da correspondência de Farias com Pierre Verger, não apenas um percurso exilar, mas principalmente elementos para compreendermos a construção do campo de estudos africanos no Brasil."

\section{LEIA-SE:}

"O trabalho de Luiza Nascimento, por sua vez, apresenta a trajetória, no exílio, do historiador brasileiro Paulo Farias. Em seu artigo, a autora descreve, a partir da correspondência de Farias com Pierre Verger, não apenas um percurso exilar, mas também fornece elementos para compreendermos a construção do campo de estudos africanos no Brasil, em países da África Ocidental como Senegal, Gana e Nigéria além do Reino Unido durante os anos 1960." 